\title{
Optimization of Local Fiscal Policies to Promote Reform of Leisure Agriculture
}

\author{
Shan Fubin \\ College of Finance and trade, BoHai University, Jinzhou 121007, P.R.China
}

351581707@qq.com

Keywords: Leisure Agriculture; Reform; Fiscal policy; Optimization

\begin{abstract}
The reform of leisure agriculture originates from innovations of managers, which cannot be separated from support of local governments. Based on analysis of necessity, it is necessary to optimize local fiscal policies to promote reform of leisure agriculture, objectives and ideas of optimizing fiscal policy are put forward on basis of motivation theory. Based on practice, basic work and main measures of optimizing fiscal policy were put forward. Fundamental work includes: classification of business entities, determination of optimization principles and accurate observation of performance of business entities. The main measures include giving tax subsidies to business entities that meet standards, giving high subsidies to business entities with outstanding innovative performance, adjusting fiscal policies according to situation of leisure agriculture and establishing a cooperation mechanism among relevant government departments.

The 19th CPC national congress put forward rural revitalization strategy which includes industrial revitalization, cultural revitalization, talent revitalization, ecological reshaping and organizational revitalization. Industrial revitalization is main content and core of rural revitalization. The structural reform of agricultural supply side is one of the main directions of rural industrial revitalization. Vigorously developing leisure agriculture is gradually becoming main content of structural reform of agricultural supply side. The integration and optimization of local fiscal policies provide the foundation and guarantee for the development of leisure agriculture.
\end{abstract}

\section{Necessity of Optimizing Local Fiscal Policies}

\section{Supporting Social Attributes of Industry}

Leisure agriculture is organic integration of agriculture, tourism, creative industries and other industries which is one of important contents of development of modern agriculture. The benefits of leisure agriculture are not only reflected in economic growth of operators and employees, but also in beautification of rural ecological environment, inheritance of rural culture, increase of employment opportunities for villagers, improvement of rural living environment and satisfaction of residents' demand for special agricultural products and leisure. The diversification of benefits shows that essential attribute of leisure agriculture should be social enterprise attribute while economic attribute is secondary attribute. The beneficiaries of reform of leisure agriculture are not only various producers and operators, but also residents and tourists[1].Therefore, it is necessary to optimize local fiscal policy from perspective of social attributes of industry.

\section{Regulation of Industrial Development Externalities}

Leisure agriculture achieves restructuring and extension in different industries and fields. As an agricultural form with obvious pull effect it has a strong correlation with other industries. The reform of leisure agriculture not only brings economic returns to investors but also benefits more people. This comes from its huge investment multiplier effect to pull closely related agricultural production, tourism, catering, accommodation, packaging design and other industries. Significant positive externalities require government incentives and subsidies to compensate for development costs of operators. In addition, negative externalities brought about by leisure agricultural production should also be noticed. Such as change of agricultural ecosystem and loss of authenticity of rural traditional culture due to commercial development. The reduction of negative effects can 
only be achieved by restricting developers and operators and relying on government regulation measures[2].

\section{Subsidizing Public Property of Industry}

Promoting industrial efficiency, improving the ecological environment, disseminating rural culture and innovating tourism projects require the government and market operators to invest resources in development and construction. Government investment is to create a good foundation and conditions for operators, while main market players are in production of agricultural products and development of tourism projects. It is embodiment of "mixed production". The development of leisure agriculture has changed industrial structure, ecological environment and inherited rural culture. These benefits are enjoyed not only by consumers but also by other "non-payers" such as villagers and related industry practitioners. which is embodiment of attribute of "quasi-public goods" in leisure agriculture. Therefore, reform of leisure agriculture needs government subsidy to investors in order to regulate behavior of managers and match behavior of government[3].

\section{Strengthening Multiple Functions of Industry}

The multi-level industrial chain and value system are constructed, new agricultural products and leisure consumer markets are created in leisure agriculture through innovative utilization of agricultural production, rural life, ecological resources and other resources by new ways. In addition, development of leisure agriculture has promoted rural construction, cultural heritage and ecological environment improvement. At present, products and services in leisure agriculture can't effectively meet diversified needs of consumers because overall innovation of industry is insufficient in China. Therefore, corresponding financial policies and measures need to be taken to promote reform of leisure agriculture. Policies can guide flow and allocation of resources, thereby expanding functional structure and overall value level of leisure agriculture which can create a wealth of products and services for consumers.

\section{Solving Difficulties of Industry}

As a new form of agriculture, leisure agriculture can't get rid of high risk. The production of leisure agriculture needs innovative thinking, new technology, high-quality practitioners and high capital investment. Therefore, threshold of reform is higher for leisure agriculture and it also contains a great investment risk. At the same time, innovation and design of leisure agriculture is easy to be imitated in practice. In addition, inadequate planning, lack of talent, incomplete financial support system, market instability and so on, which have also restricted reform of leisure agriculture. Solving these risks and difficulties requires government's fiscal policies to improve operators' ability.

\section{Objective and Thinking of Optimizing Local Fiscal Policies}

\section{Objective of Optimizing Local Fiscal Policies}

Guide reform direction of leisure agriculture by fiscal policy. The reform of regional leisure agriculture needs overall planning and collaborative promotion. The construction of appropriate fiscal policies can effectively cooperate with government's general policies and strategies. The behavior of various business entities is guided through financial policy then leisure agriculture can achieve scientific development[4].

Cultivate leisure agriculture's new kinetic energy relying on fiscal policy. The task of leisure agriculture reform is to promote rational allocation and utilization of human resources, culture, ecology and organization. Constructing a scientific government financial policy system will help to leverage more social funds and resources into leisure agriculture. This is conducive to improving industrial value system, training new business entities, building talent system, improving basic condition. Then provide a new impetus for the reform of leisure agriculture.

Adjusting imbalance of leisure agriculture reform based on fiscal policy. The reform of leisure agriculture is a systematic project which inevitably leads to various problems and unbalanced development. Use the government's fiscal policies to coordinate relations among regions, industries, subjects and departments. 


\section{Thinking of optimizing local fiscal policies}

The reform of leisure agriculture is rooted in the dynamic system of industry including endogenous and exogenous driving forces. The endogenous power comes from innovation of industrial development mode which is coordinated by management subject, construction subject and management subject. Exogenous power comes from financial system, service platform, infrastructure and other conditions. Endogenous power can achieve rational and efficient allocation of resources, exogenous driving force provides foundation and guarantee for development of leisure agriculture.

The core idea of optimizing local fiscal policy to promote reform of leisure agriculture is how to make use of policy to promote improvement and promotion of power system of leisure agriculture.

Under core idea, optimize and implement fiscal policy system using differential support as basic guideline. That is to say, different fiscal policies should be adopted in accordance with different innovative contents and different demands of various business models. This can improve performance of fiscal policy in reform of leisure agriculture[5].

Under core ideas and basic guideline, based on main tasks and specific contents of regional leisure agriculture reform existing problems in implementation of current fiscal policy are summarized then needs of various business models and business entities are analyzed. Based on cultivating motive force of innovation and development, main contents of fiscal policy optimization are determined and main measures of fiscal policy implementation are put forward[6].

\section{Foundation of Optimizing Local Fiscal Policies}

\section{Classification of Operators of Leisure Agriculture}

In practice, the operating subjects of leisure agriculture include rural areas, agricultural parks, agricultural production bases, agricultural manors and other specific operating subjects. These operators should be counted and classified before policy is issued. The standard of classification is scale and performance. Appropriate financial support should be given to different types of business entities and made timely adjustments based on changes. By classifying types, policy funds can be gathered into demonstration areas, gathering areas, key villages, leading enterprises and other operating subjects with development prospects.

\section{Determination of Basic Principles on Fiscal Policy Optimization}

The rapid development of leisure agriculture puts forward higher requirements for fiscal policy. The basic principles of optimizing fiscal policy are to guide and standardize simultaneously, pay equal attention to both quantity and quality, highlight key points and stress practical results. That is to say, Give full play to role of fiscal policy in guiding and standardizing, so that business entities in line with standards continue to innovate products and services, their innovative behavior more accord with positioning and objectives of regional leisure agriculture[7]. At the same time, the degree of support should be connected with the benefit, scale and contribution of the operators, so that the effect of subsidized funds is more significant.

\section{Accurately Observe Performance of Business Entities}

To ensure effectiveness of local fiscal policies, premise is that government should be able to accurately observe real benefits and business scale of operators. In practice, because government cannot observe in real time, it is necessary to avoid fraud of operators to obtain financial subsidies. In order to reduce impact of information asymmetry on government decision-making, third-party subjects can be introduced to inspect and evaluate operating subjects. For example, leisure agriculture association and cooperative organization can be chosen as third-party subjects. The government and third-party subjects make clear and operable agreements, so government can accurately grasp real income situation and operation behavior of operators. 


\section{Main Measures to Optimize Local Fiscal Policy}

\section{Tax Subsidies are Given to Business Entities that Meet Standards}

In areas where basic conditions for development of leisure agriculture are good and overall value of industry is high, corresponding tax preferences need to be given in order to promote reform. Tax preference is a "health care" factor in reform of leisure agriculture, so its incentive effect is small. In practice, tax preference standard should not be too high and it is best to take the form of subsidy. According to basic conditions, business scale, service items, service level, business ability, operating costs and other factors, determine standard of tax subsidy. Based on these factors, threshold of tax subsidies be set. That is to set up a higher tax subsidy qualification [8]. Only those who have higher innovation performance or scale of operation can get preferential tax revenue. In this way, it can improve satisfaction of operators and strengthen their confidence and motivation to participate in the reform.

\section{High Subsidies are Given to Business Entities with Significant Innovation Performance}

The purpose of fiscal policy is to stimulate operators with a certain scale and performance level to work hard to cultivate local brand of leisure agricultural. Fiscal policy should change the practice of universal benefit and make government's support more precise and targeted. In practice, subsidy of local fiscal policy should focus on highly efficient and innovative business entities. That is to give support to those business entities with significant benefits, exemplary and driving roles. Incentives should be subsidized to leading enterprises, cooperative organizations and other influential entities[9]. At the same time, amount of subsidies should be higher. Through high subsidies, provide support for business entities with better innovation performance to stimulate their innovation which includes innovation of formats, technological innovation, project innovation and mode innovation.

\section{Timely Adjustment Fiscal Policy According to Level of Regional Leisure Agriculture}

The local fiscal policy should be changed in a timely manner according to actual situation of regional leisure agriculture. First of all, it is necessary to integrate the current relevant policies and establish a special subsidy policy for leisure agriculture, which can make policy resources concentrate and play a role. Secondly, in addition to regular subsidies, excellent business entities should be given higher incentives to meet their individual needs. In addition, financial incentives should be gradually reduced and subsidies for business entities' loans should be gradually increased. Establish a financial service platform led by government and participated by financial institutions. Using the platform, government's input can drive more funds to converge to leisure agriculture[10].

Establish an Inter-departmental Cooperation Mechanism to Promote Reform of Leisure Agriculture

The reform of leisure agriculture involves many government departments, such as agriculture, land, culture, tourism, industry and commerce, which all have corresponding responsibilities and powers. In practice, in order to maximize utilization of policy resources, all departments should fully communicate and cooperate with each other under basic goal of promoting sustainable development of local leisure agriculture. Through cooperation mechanism, policies of various departments can be matched and coordinated with each other, so effectiveness of all measures can be guaranteed to be maximized.

\section{Summary}

The core idea of optimizing fiscal policy to promote reform of regional leisure agriculture is to foster innovative force of industry. Taking advantage of optimized fiscal policies to stimulate and restrain behavior of operators, at same time drive other related subjects to actively participate in leisure agriculture. The guideline of optimizing fiscal policy is adopting differentiated support to play an important role of fiscal policy. The government should adopt targeted fiscal policy according to content of different types of business models and actual needs of different types of business entities. The measures to optimize local fiscal policies must focus on effectiveness. 


\section{Acknowledgements}

This study was partially supported by Liaoning Province Social Science Fund Project, PR China.

\section{References}

[1] SUN Wenji. Think about Financial Support on China's Agricultural Modernization. Issues in Agricultural Economy.34(2013)29-33.

[2] GAO Bo. Optimization of Financial Support for Agriculture in Inner Mongolia Autonomous Region. Inner Mongolia Agricultural University. Hohhot City Inner Mongolia Autonomous Region. 2016,Doctor.

[3] WU Zhongying. Optimization of Fiscal Support Policy Based on Structural Reform of Agricultural Supply Side, Hebei University of Economics and Business. Shijiazhuang City Hebei Province.2018, Master.

[4] WEN Yi. The Shock Effect Study on the Impact of Financial Policies and Fiscal Expenditures on the Agricultural Products' Prices in China. Canadian Social Science. 2 (2015)141-145.

[5] CHENG Yu,YE Xingqing.Learn From International Experience and Reform China's Agricultural Support Policy. Study \& Exploration.39(2017)113-119.

[6] ZHANG Jing. Overall Thinking on Perfecting Agricultural Support Policy Under the New Norma--Learn From the New Trend of US Agricultural Policy. World Agriculture.39(2018)63-70.

[7] WEN Xiaocai. Research on Fiscal Policy of Local Governments to Promote Farmland Circulation--Take Henan Province as an Example. Public Finance Research.35(2014) 58-61.

[8] Information on http://www.moa.gov.cn

[9] ZHANG Xiaoshan. Several Grasps of Implementing Rural Revitalization Strategy. People's Tribune.26(2017)72-74.

[10] YE Xing. Outline of China's Rural Revitalization Strategy in the New Era. Reform.30(2018)65-73. 